\title{
Standardization of various factors for production of adventitious roots in selected varieties of Withania somnifera and estimation of total withanolides by High Performance Liquid Chromatography
}

\section{Sindhu Rangaraju, A.N. Lokesha and Chenna Reddy Aswath}

Division of Floriculture and Medicinal Crops ICAR-Indian Institute of Horticultural Research, Hesaraghatta Lake Post, Bangalore-89

\begin{abstract}
Withania somnifera (Dunal) popularly known as Ashwagandha, "Winter Cherry" and "Indian Ginseng”. Its roots and leaves are used in a number of preparations for their anti-inflammatory, anticonvulsive, antitumor properties besides promoting vigour and stamina. Ashwagandha contains very high concentration of metabolites like steroidal lactones (Withanolides), alkaloids and flavonoids, so it is used in more than 200 commercially ayurvedic formulations. The annual requirement of Withania sominifera in India is about 9127 MT where as the estimated production in India is only 5905 MT. This requirement can be met by mass cultivation of adventitious roots using bioreactors. Adventitious roots induced by this form are considered to be genetically uniform, true to its type that gives rise to mass production of desired pharmaceutical compound. Seeds of varieties like Jawahar Ashwagandh-20 (JA-20), Arka Ashwagandha (AA), IIHR WS-48 and IIHR WS-32 have been raised in in-vitro conditions. Adventitious roots were induced from in-vitro leaves by varying factors. Half strength MS medium yielded more roots than full strength MS medium, combination of IAA and IBA (ranging from $0.025-0.01 \mathrm{mg} / \mathrm{l}$ ) were found to be ideal for adventitious root induction for each variety. Sucrose concentration (3-4\%) in half strength MS media yielded more adventitious roots, with a light intensity of 16 hours photoperiod than darkness.
\end{abstract}

KEY WORDS: WITHANIA SOMNIFERA (DUNAL), IAA, IBA, HIGH PERFORMANCE LIQUID CHROMATOGRAPHY

\section{ARTICLE INFORMATION:}

${ }^{*}$ Corresponding Author: sindhurangaraju63@gmail.co.in Received $1^{\text {st }}$ July, 2018

Accepted after revision $19^{\text {th }}$ Sep, 2018

BBRC Print ISSN: 0974-6455

Online ISSN: 2321-4007 CODEN: USA BBRCBA

Thomson Reuters ISI ESC / Clarivate Analytics USA and

$\because 0^{\circ}$ Crossref Indexed Journal

NAAS Journal Score 2018: 4.31 SJIF 2017: 4.196

- A Society of Science and Nature Publication, Bhopal India 2018. All rights reserved.

Online Contents Available at: http//www.bbrc.in/

DOI: $10.21786 / \mathrm{bbrc} / 11.3 / 14$ 


\section{INTRODUCTION}

Withania somnifera (Dunal) popularly known as Ashwagandha, Indian ginseng and Winter cherry belongs to the family Solanaceae. The plant's Latin name literally means, "sweat of a horse" due to the scent of the roots. The plant is commonly found in Africa, Mediterranian, India and North America. It is an erect branched under shrub up to $1.25 \mathrm{~m}$ in height, minute, smooth and shiny hairs throughout the plant. Leaves are ovate, with hairs and soft to touch. Flowers are greenish, the roots are fleshy, papery and whitish brown in color. The stems are around 3 to 4 feet in height. One plant survives for up to 4 to 5 years. Its stem contains fiber like texture. The leaves are oval shaped, 2 to 4 inches long and contain fiber. The flowers are blooming at the base of the stems are small, somewhat long with chimney shape and yellowish green in color. The flowers bloom from the base of the leaves and become red when wipe. The seeds are small, heart shaped, smooth and flat. The roots are rough, white from within, strong, transparent, thick and one to one and half feet long, (Geetha et al., 2018).

In Ayurveda and Unani medications the herb is majorly used for its high rejuvenating power. It is called as "The natural stress buster" due to its ability in making the human body copes with different kinds of stress (Rao, 2012). The roots of Ashwagandha help in boosting immunity power of the body. It is commonly prescribed for hiccup, bronchitis, dropsy, rheumatism and female disorders, the roots of this plant also prescribed for general sexual weakness in human beings (Kattimani et al., 2000). Its roots and leaves are used in a number of preparations for their anti-inflammatory, anticonvulsive, antitumor, immuno-suppressive and antioxidant properties besides promoting vigor and stamina. Ashwagandha is increasingly becoming a popular adaptogenic herb and is available throughout the western world as a dietary supplement. Ashwagandha contains very high concentration of metabolites like steroidal lactones (Withanolides), alkaloids and flavonoids, so it is used in more than 200 commercially ayurvedic formulations.

Adventitious roots are the roots that are induced at unusual sites such as roots forming on leaves, which grow and branch rapidly (Dubrovsky and Rost., 2003). The roots induced by this form are considered to be genetically uniform, true to its type, that gives rise to mass production of desired pharmaceutical compound (Goel et al ., 2009). Adventitious root cultures provide a preferred platform to produce commercially important secondary metabolites (Khan et al 2017). Adventitious roots can harbor medicinally important compounds through different strategies like elicitation, temperature stress etc., (Rani et al., 2017).
The technique of micro propagation is applied with the objective of enhancing the rate of multiplication. Through the culture over a million of plants can be grown from a small piece of plant tissue within 12 months. Such proliferative rate of multiplication cannot be expected by any in-vivo methods. Large scale production through plant in-vitro regeneration will provide a means of putting the plant onto the market at lower prices. In addition, the technique is cost effective, relatively simple and can be performed by semi-skilled persons. A sustained supply of the source material often becomes difficult due to the factors like environmental changes, cultural practices, diverse geographical distribution, labour cost, selection of the superior plant stock, over exploitation by pharmaceutical industry (Kaur et al 2017)

Optimization of various tissue culture techniques become very important to explore $W$. somnifera at different aspects, as plants obtained from fields fileds are not enough for all in vitro studies. Therefore, effcient tissue culture techniques like, micropropaogation, regeneration, organogenesis, hairy root production, etc. have been established, (Vibha pandey et al. 2017).

The requirement of dried plant material for withanolides drug production in India is estimated to be 9127 tonnes against the annual production of 5905 tonnes (Sharda et al., 2007). Moreover, field cultivation is time consuming, laborious and not able to meet the Ashwagandha global market requirement (Sivanandan et al., 2012b; 2013a). To improve the commercial cultivation of Ashwagandha, biological advances must be made that should either increase yield or reduce time gap to assure quality (Banerjee et al., 1994).

The provision of alternative sources of Withania somnifera by encouraging its cultivation will go a long way in reducing their heavy dependence on the wild populations and also major diseases of plant like seed rot and blight can be overcome. The main objective of this research is to develop a reproducible protocol for adventitious root induction from in-vitro leaves, and comparative analysis of withanolides present in in vitro adventitious roots roots of different varieties and selection of best variety for mass propagation in bioreactors.

\section{MATERIALS AND METHODS}

Selection and establishment of plant material for micropropogation.

Seeds of four high yielding varieties of Withania somnifera like JA-20 (released variety from MPKVV, Madhya Pradesh) used as check in AICRP national trials, Arka Ashwagandha (released variety from IIHR, Bangalore), IIHR WS-32 and IIHR WS-48 were selected for the experiment.

The seeds were soaked in $300 \mathrm{ppm}$ of gibberellic acid for 12 hours and washed with water. The seeds were 
pre-treated using $100 \mathrm{mg}$ Dithane M-45 fungicide for 15 minutes, washed with sterile water followed by $70 \%(\mathrm{v} / \mathrm{v})$ ethanol for 1 minute, washed with sterile water and then with $0.1 \%(\mathrm{w} / \mathrm{v})$ sodium hypochlorite $(5 \%(\mathrm{w} / \mathrm{v})$ available chlorine, NICE Kochi Solution) for 4 minutes. Then seeds were washed with sterile double distilled water 2-3 times to remove traces of sodium hypochlorite and dried. The seeds were then inoculated into half strength MS medium (Murashige and Skoog , 1962).

\section{Procedure for adventitious root induction}

Leaves from two month old explants were taken for production of adventitious roots, before inoculation, leaves were cut in middle with sterilized scalpel and placed on MS culture medium with the adaxial surface down. Different factors were varied-

1. Strength of medium: Half strength and full strength MS medium with selected combination of auxins were used to study adventitious root induction.

2. Sucrose concentration: Carbohydrate source plays an important role in maintaining osmoticum in plant tissue culture. Root initiation and development is a high energy process which requires the expense of available metabolic substrates such as sugars. Sucrose at different concentrations (2-7\%) were tried.

3. Auxin treatment: In order to determine the optimal conditions for adventitious root induction, we tested various concentration of auxins (IAA and IBA) ranging from $0.025-0.01 \mathrm{mg} / \mathrm{L}$ in 5 different combinations and compared it with control (without IAA and IBA).

4. Light intensity: The cultures in half strength MS medium with selected auxin combination were incubated at $25 \pm 2{ }^{\circ} \mathrm{C}$ with 16 hours photoperiod under cool fluorescent light and for dark treatment the bottles were placed in shelves without light.

The adventitious roots were observed after 15 days and parameters like number of roots per explant and percentage of explants response for root induction were studied.

The roots were subjected for HPLC analysis to estimate the total withanolide content.

5. Extraction of bioactive principles from W.somnifera

The adventitious roots extracted from in-vitro were washed twice with milli- $Q$ water to remove the traces of agar, dried and powder dried using pestle and mortar. They were assessed for different components that contribute to total withanolides. The analysis was carried out by HPLC method (Agarwal and Murali, 2010). Two grams of dry root powder was extracted with $50 \mathrm{~mL}$ of methanol on boiling water bath for about 20 minutes and transfer the extract to a $250 \mathrm{~mL}$ beaker. Repeat the process 3-4 times till the extract was colorless. Then collected all the extracts and made up the volume to $100 \mathrm{~mL}$ with methanol, mixed well and filtered through 0.45 micron membrane filter and these were subjected to analysis by HPLC with Photo Diode Array detector. Seven standards such as Withanoside IV, Withanoside V, Withaferine A, Withanolide A, Withanolide B, 12- deoxy Withanostramolide and Withanone were used to quantify the amount of various withanolides present in the root samples. Chromatogram was recorded at $227 \mathrm{~nm}$ wavelength and later calculate the contents of individual withanolides by the using the formula and expressed as $\mathrm{mg} / 100 \mathrm{~g}$ dry weight basis.

Area of the sample $x$

Standard Wt. $(\mathrm{mg}) \times$

Sample dilution $x$

Purity of standard

Area of the standard $x$

Standard dilution $\times$

sample weight $(\mathrm{mg}) \times 100$

\section{RESULTS AND DISCUSSION}

The results from the present study demonstrated that standardization of different factors like strength of the medium, effect of photoperiod, sucrose concentration , combinations of auxins at different concentrations is essential for effective adventitious root induction in Withania somnifera.

In this study to determine the effects of media strength half strength MS medium with a combination of $0.25 \mathrm{mg} / \mathrm{l}$ IAA and $0.75 \mathrm{mg} / \mathrm{l}$ IBA had higher number of induction response and also higher number of roots per explants (Table no 1 and 2). The results of the present study is similar to results of the previous studies on adventitious root induction in Withania somnifera by Wadegaonkar et al (2006) and Praveen and Murthy (2010), where half strength MS medium was chosen suitable for adventitious root induction. It contradicts with Yin et al (2013) induced adventitious roots in Pseudostellaria heterophylla in full strength MS medium with $3 \mathrm{mg} / \mathrm{L}$ IBA using root explants.

Highest root induction response (98.2\% in JA 20) and highest number of roots per explant (16 roots in WS 32) was observed in bottles placed under 16 hours photoperiod compared to darkness in all the varieties of Withania somnifera (Table 3 and 4). Explants incubated under darkness induced profuse callusing which subsequently turned brownish and hindered the induction of roots. Roots initiated were thick and longer in braches under 16 hours photoperiod compared to thin and brittle roots in darkness. 
Table 1. Effect of strength of the medium on the induction response (\%)

\begin{tabular}{|l|l|l|l|l|}
\hline Treatment & Arka Ashwagandha & JA 20 & IIHR WS 32 & IIHR WS 48 \\
\hline Half MS & $98.00 \pm 0.173 \mathrm{a}$ & $98.00 \pm 0.520 \mathrm{a}$ & $98.60 \pm 0.387 \mathrm{a}$ & $97.40 \pm 0.316 \mathrm{a}$ \\
\hline Full MS & $95.4 \pm 0.173 \mathrm{~b}$ & $96.20 \pm 0.520 \mathrm{~b}$ & $96.40 \pm 0.387 \mathrm{~b}$ & $96.40 \pm 0.316 \mathrm{~b}$ \\
\hline
\end{tabular}

Table 2. Effect of strength of the medium on number of roots per explant

\begin{tabular}{|l|l|l|l|l|}
\hline Treatment & Arka Ashwagandha & JA 20 & IIHR WS 32 & IIHR WS 48 \\
\hline Half MS & $13.80 \pm 0.070 \mathrm{a}$ & $13.60 \pm 0.173 \mathrm{a}$ & $14.20 \pm 0.173 \mathrm{a}$ & $12.60 \pm 0.141 \mathrm{a}$ \\
\hline Full MS & $13.20 \pm 0.070 \mathrm{~b}$ & $13.20 \pm 0.173 \mathrm{~b}$ & $13.80 \pm 0.173 \mathrm{~b}$ & $12.40 \pm 0.141 \mathrm{~b}$ \\
\hline
\end{tabular}

Table 3. Effect of photoperiod on adventitious root induction

\begin{tabular}{|c|c|c|c|c|c|c|c|c|}
\hline \multirow{2}{*}{ Treatments } & \multicolumn{4}{|c|}{ Induction Response (\%) } & \multicolumn{4}{|c|}{ No of roots per explant } \\
\hline & $\mathrm{AA}$ & JA 20 & WS 32 & WS 48 & AA & JA 20 & WS 32 & WS 48 \\
\hline $16 \mathrm{hr}$ photoperiod & 97.8 & 98.2 & 97.6 & 97.6 & 13.5 & 15.25 & 16 & 16.45 \\
\hline Darkness & 91.8 & 91.6 & 92 & 91.8 & 5.1 & 5.1 & 5.05 & 5.6 \\
\hline S.Em & \multicolumn{4}{|c|}{0.2151} & \multicolumn{4}{|c|}{0.245} \\
\hline CD 5\% & \multicolumn{4}{|c|}{0.619} & \multicolumn{4}{|l|}{1.75} \\
\hline CD 1\% & \multicolumn{4}{|l|}{0.81} & \multicolumn{4}{|l|}{2.36} \\
\hline $\mathrm{CV}$ & \multicolumn{4}{|c|}{$0.717 \%$} & \multicolumn{4}{|c|}{$4.69 \%$} \\
\hline
\end{tabular}

Table 4. Effect of photoperiod on number of days taken for adventitious root induction

\begin{tabular}{|l|l|l|l|l|}
\hline Treatment & Arka Ashwagandha & JA 20 & IIHR WS 32 & IIHR WS 48 \\
\hline 16 hours Photoperiod & $24.00 \pm 0.316 \mathrm{a}$ & $26.00 \pm 0.346 \mathrm{a}$ & $26.60 \pm 0.141 \mathrm{a}$ & $26.00 \pm 0.346 \mathrm{a}$ \\
\hline Darkness & $15.00 \pm 0.316 \mathrm{~b}$ & $14.80 \pm 0.346 \mathrm{~b}$ & $15.80 \pm 0.141 \mathrm{~b}$ & $14.80 \pm 0.346 \mathrm{~b}$ \\
\hline
\end{tabular}

Praveen and Murthy (2010) also established adventitious roots from leaf segments of Withania somnifera on half strength MS medium(0.8\%) agar with $0.5 \mathrm{mg} / \mathrm{L}$ IBA, 30g/L sucrose incubated under 16 hours photoperiod with 100\% of explants response for root induction.

Table 1- Values are mean \pm standard error of five replications in three independent experiments, each with three explants per treatment. Means followed by the same letter are not significantly different at $\mathrm{P}<0.05$ according to Duncan multiple range test in all tables Data were scored after15 days of culture

Table 2- Values are mean \pm standard error of five replications in three independent experiments, each with three explants per treatment. Means followed by the same letter are not significantly different at $\mathrm{P}<0.05$ according to Duncan Range Multiple Test. Data were scored after 15 days of culture

\begin{tabular}{|l|l|l|l|l|}
\hline \multicolumn{3}{|c|}{ Table 5. Effect of Sucrose concentration on adventitious root induction response (\%) } \\
\hline $\begin{array}{l}\text { Treatments (Induction } \\
\text { response \%) }\end{array}$ & Arka Ashwagandha & JA 20 & WS 32 & WS 48 \\
\hline $2 \%$ Sucrose & $88.00 \pm 0.397 \mathrm{~b}$ & $82.40 \pm 0.465 \mathrm{~b}$ & $80.40 \pm 0.389 \mathrm{~b}$ & $88.20 \pm 0.499 \mathrm{~b}$ \\
\hline $3 \%$ Sucrose & $96.60 \pm 0.397 \mathrm{a}$ & $86.80 \pm 0.465 \mathrm{a}$ & $85.80 \pm 0.389 \mathrm{a}$ & $98.40 \pm 0.499 \mathrm{a}$ \\
\hline $4 \%$ Sucrose & $79.40 \pm 0.397 \mathrm{c}$ & $78.60 \pm 0.465 \mathrm{c}$ & $75.40 \pm 0.389 \mathrm{c}$ & $77.00 \pm 0.499 \mathrm{c}$ \\
\hline $5 \%$ Sucrose & $61.40 \pm 0.397 \mathrm{~d}$ & $61.60 \pm 0.465 \mathrm{~d}$ & $61.20 \pm 0.389 \mathrm{~d}$ & $61.00 \pm 0.499 \mathrm{~d}$ \\
\hline $6 \%$ Sucrose & $33.60 \pm 0.397 \mathrm{e}$ & $35.60 \pm 0.465 \mathrm{e}$ & $31.60 \pm 0.389 \mathrm{e}$ & $34.60 \pm 0.499 \mathrm{e}$ \\
\hline $7 \%$ Sucrose & $10.20 \pm 0.397 \mathrm{f}$ & $11.00 \pm 0.465 \mathrm{f}$ & $10.20 \pm 0.389 \mathrm{f}$ & $10.60 \pm 0.499 \mathrm{f}$ \\
\hline
\end{tabular}




\begin{tabular}{|c|c|c|c|c|}
\hline Treatments & Arka Ashwagandha & JA 20 & WS 32 & WS 48 \\
\hline 2\% Sucrose & $11.40 \pm 0.319 c$ & $11.80 \pm 0.331 \mathrm{c}$ & $10.60 \pm 0.294 c$ & $11.80 \pm 0.261 \mathrm{c}$ \\
\hline 3\% Sucrose & $17.60 \pm 0.319 \mathrm{a}$ & $17.20 \pm 0.331 \mathrm{a}$ & $15.00 \pm 0.294 a$ & $17.20 \pm 0.261 \mathrm{a}$ \\
\hline 4\% Sucrose & $12.80 \pm 0.319 b$ & $14.00 \pm 0.331 b$ & $12.40 \pm 0.294 b$ & $14.20 \pm 0.261 b$ \\
\hline 5\% Sucrose & $8.80 \pm 0.319 d$ & $10.20 \pm 0.331 d$ & $9.8 \pm 0.294 c$ & $10.40 \pm 0.261 d$ \\
\hline $6 \%$ Sucrose & $7.40 \pm 0.319 e$ & $7.60 \pm 0.331 \mathrm{e}$ & $8.60 \pm 0.294 \mathrm{e}$ & $7.40 \pm 0.261 \mathrm{e}$ \\
\hline 7\% Sucrose & $5.40 \pm 0.319 \mathrm{f}$ & $5.60 \pm 0.331 \mathrm{f}$ & $5.20 \pm 0.294 \mathrm{e}$ & $5.40 \pm 0.261 \mathrm{f}$ \\
\hline
\end{tabular}

\begin{tabular}{|c|c|c|c|c|}
\hline Treatments & Arka Ashwagandha & JA 20 & WS 32 & WS 48 \\
\hline $0 \mathrm{IAA}+0 \mathrm{IBA}$ & $0.000 \pm 0.284 \mathrm{f}$ & $0.000 \pm 0.330 f$ & $0.000 \pm 0.614 f$ & $0.000 \pm 0.703$ \\
\hline $0.25 \mathrm{IAA}+0.75 \mathrm{IBA}$ & $96.60 \pm 0.284 \mathrm{a}$ & $97.20 \pm 0.330 \mathrm{a}$ & $85.80 \pm 0.614 b$ & $98.40 \pm 0.703$ \\
\hline $0.5 \mathrm{IAA}+0.5 \mathrm{IBA}$ & $80.80 \pm 0.284 c$ & $80.60 \pm 0.330 c$ & $80.40 \pm 0.614 c$ & $82.20 \pm 0.703$ \\
\hline $0.75 \mathrm{IAA}+0.25 \mathrm{IBA}$ & $76.80 \pm 0.284 \mathrm{~d}$ & $77.40 \pm 0.330 \mathrm{~d}$ & $75.60 \pm 0.614 d$ & $75.00 \pm 0.703$ \\
\hline $0 \mathrm{IAA}+1 \mathrm{IBA}$ & $83.6 \pm 0.284 \mathrm{~b}$ & $82.40 \pm 0.330 \mathrm{~b}$ & $97.6 \pm 0.614 \mathrm{a}$ & $85.60 \pm 0.703$ \\
\hline $1 \mathrm{IAA}+0 \mathrm{IBA}$ & $72.4 \pm 0.284 \mathrm{e}$ & $68.00 \pm 0.330 \mathrm{e}$ & $67.80 \pm 0.614 \mathrm{e}$ & $65.00 \pm 0.703 e$ \\
\hline
\end{tabular}

\begin{tabular}{|c|c|c|c|c|}
\hline Treatments & Arka Ashwagandha & JA 20 & WS 32 & WS 48 \\
\hline $0 \mathrm{IAA}+0 \mathrm{IBA}$ & $0.000 \pm 0.257 \mathrm{~d}$ & $0.000 \pm 0.245 \mathrm{e}$ & $0.000 \pm 0.238 f$ & $0.000 \pm 0.371 \mathrm{e}$ \\
\hline $0.25 \mathrm{IAA}+0.75 \mathrm{IBA}$ & $17.60 \pm 0.257 \mathrm{a}$ & $17.20 \pm 0.245 a$ & $15.00 \pm 0.238 b$ & $17.20 \pm 0.371 \mathrm{a}$ \\
\hline $0.5 \mathrm{IAA}+0.5 \mathrm{IBA}$ & $13.80 \pm 0.257 b$ & $13.80 \pm 0.245 b$ & $14.20 \pm 0.238 \mathrm{c}$ & $12.20 \pm 0.371 \mathrm{c}$ \\
\hline $0.75 \mathrm{IAA}+0.25 \mathrm{IBA}$ & $11.60 \pm 0.257 \mathrm{c}$ & $11.60 \pm 0.245 c$ & $11.60 \pm 0.238 d$ & $13.00 \pm 0.371 b c$ \\
\hline 0 IAA+1 IBA & $13.60 \pm 0.257 \mathrm{~b}$ & $14.40 \pm 0.245 b$ & $17.40 \pm 0.238 a$ & $13.60 \pm 0.371 \mathrm{~b}$ \\
\hline $1 \mathrm{IAA}+0 \mathrm{IBA}$ & $11.40 \pm 0.257 c$ & $9.20 \pm 0.245 d$ & $8.80 \pm 0.238 \mathrm{e}$ & $9.80 \pm 0.371 d$ \\
\hline
\end{tabular}

Table 3- Values are mean \pm standard error of five replications in three independent experiments, each with three explants per treatment. Data were scored after 15 days of culture. Growth Conditions- Media- Half MS supplement with selected auxin combination, photoperiod-16 hours, culture period- 3 weeks at $25 \pm 2{ }^{\circ} \mathrm{C}$

Table 4- Values are mean \pm standard error of five replications in three independent experiments, each with three explants per treatment. Means followed by the same letter are not significantly different at $\mathrm{P}<0.05$ according to Duncan Range Multiple Test. Data were scored after 15 days of culture. Growth ConditionsMedia- Half MS supplement with selected auxin combination, photoperiod-16 hours and complete darkness, culture period- 3 weeks at $25 \pm 2^{\circ} \mathrm{C}$

Carbohydrate plays an important role in maintaining osmoticum in plant tissue culture. Sucrose is considered as an unquestionably important carbon and energy source which is found in abundance in phloem sac involved in developmental process. From the observations of the above study, the optimal condition for adventitious root induction in Withania somnifera was half strength MS medium with 3\% sucrose concentration, (Table 5 and 6).

It has been documented earlier that a sucrose concentration (3\%) was suitable for hairy root growth, whereas a too low or too higher a concentration of sucrose was adverse to adventitious root growth in $W$. somnifera (Sivanandhan et al. 2012 a). A lower concentration cannot provide enough energy and therefore may not be able to act as building blocks. However, higher sucrose concentration exhibited negative effect in growing cells. Nagella and Murthy (2010) recorded that $3 \%$ sucrose was suitable for biomass accumulation and withanolide A production in cell suspension culture of W.somnifera. Sucrose at higher concentrations in the nutrient medium normally reduces cell biomass due to the increase of osmotic potential which subsequently reduces the uptake of nutrients. A similar result was obtained by Zhang et al. (2012) in Periploca sepium adventitious root culture and by Sivanandhan et al. (2012 a) in W. somnifera adventitious root and hairy root cultures. 


\begin{tabular}{|l|l|l|l|l|l|}
\hline \\
Table 9. Analysis of bioactive principles from W. sominifera using HPLC. \\
\hline Variety names & Withanoside IV & Withaferin A & Withanolide A & Withanolide B & Total Withanolide \\
\hline Arka Ashwagandha & $0.061 \pm 0.001 \mathrm{a}$ & $0.023 \pm 0.000 \mathrm{a}$ & $0.00{ }_{ \pm} 0.000 \mathrm{~b}$ & $0.000 \pm 0.000 \mathrm{~b}$ & $0.084 \pm 0.001 \mathrm{a}$ \\
\hline JA 20 & $0.018 \pm 0.001 \mathrm{~d}$ & $0.018 \pm 0.000 \mathrm{c}$ & $0.002 \pm 0.000 \mathrm{a}$ & $0.005 \pm 0.000 \mathrm{a}$ & $0.043 \pm 0.001 \mathrm{~d}$ \\
\hline IIHR WS 32 & $0.0034 \pm 0.001 \mathrm{~b}$ & $0.022 \pm 0.000 \mathrm{~b}$ & $0.000 \pm 0.000 \mathrm{~b}$ & $0.000 \pm 0.000 \mathrm{~b}$ & $0.057 \pm 0.001 \mathrm{~b}$ \\
\hline IIHR WS 48 & $0.030 \pm 0.001 \mathrm{c}$ & $0.017 \pm 0.000 \mathrm{~b}$ & $0.000 \pm 0.000 \mathrm{~b}$ & $0.000 \pm 0.000 \mathrm{~b}$ & $0.047 \pm 0.000 \mathrm{c}$ \\
\hline
\end{tabular}

The lowest induction response was observed in 7\% sucrose concentration, from this result it was noticed that the number of roots per explant started decreasing at a higher root concentration of 5\% and above. Higher amount of sucrose can retard the development of cultured cells (Wu et al., 2006) by causing cessation of the cell cycle when other nutrients are limited (Gould et al., 1981).

Table 5- Values are mean \pm standard error of five replications in three independent experiments, each with three explants per treatment. Means followed by the same letter are not significantly different at $\mathrm{P}<0.05$ according to Duncan Range Multiple Test. Data were scored after15 days of culture. Growth ConditionsMedia- Half MS supplement with selected auxin combination, photoperiod-16 hours, culture period-3 weeks at $25 \pm 2^{\circ} \mathrm{C}$

Table 6- Values are mean \pm standard error of five replications in three independent experiments, each with three explants per treatment. Means followed by the same letter are not significantly different at $\mathrm{P}<0.05$ according to Duncan Range Multiple Test. Data were scored after15 days of culture. Growth ConditionsMedia- Half MS supplement with selected auxin combination, photoperiod-16 hours, culture period-3 weeks at $25 \pm 2^{\circ} \mathrm{C}$.

Development of roots or shoots from explants involved in organogenesis depends on morphogenetic potentiality of the cells. Dedifferentiation, induction of organogenesis pathway and development of organ are the three distinct stages during organogenesis (de Kler et al., 1997). Supplementation of exogenous auxin is essential for adventitious root development (Pop et al., 2011). IAA and IBA induced adventitious roots from leaf explants after 12 days of culture. Protuberances developed in leaf explants within a week from the cut ends and adventitious roots directly developed from these protuberances in another week. The percentage of explants response for root induction and number of roots initiated per explants were recorded after 3 weeks of culture.
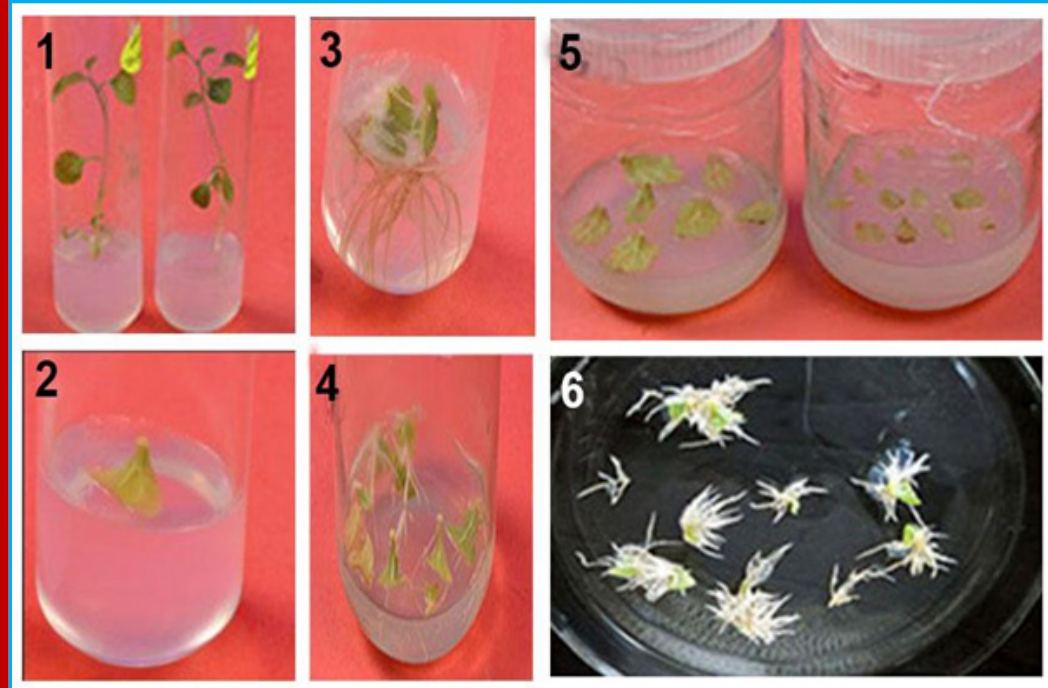

FIGURE 1A. 1) 2 month old explant of Withania somnifera ,2) culturing of leaves for adventitious root induction 3) best hormone treatment for adventitious root induction 4) adventitious root induction observed after 7 days of culture 5) mass production of adventitious roots in bottles 6) adventitious roots are washed and measured. Growth Conditions- Media- Half MS supplement with selected auxin combination, photoperiod-16 hours, culture period- 3 weeks at $25 \pm 2^{\circ} \mathrm{C}$ 


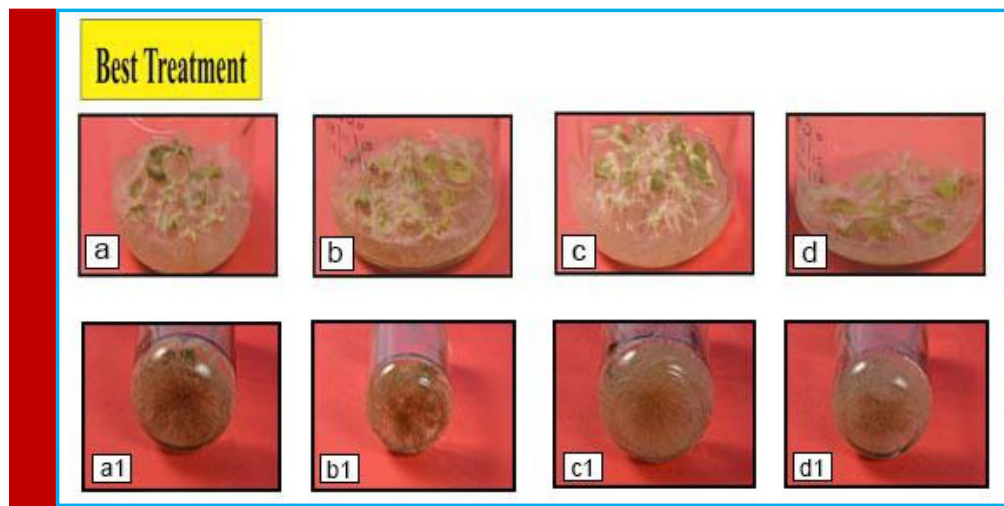

FIGURE 1B. Best culture conditions for mass production of adventitious roots in bottles. a, a1- Arka Ashwagandha variety with an auxin concentration of $0.25 \mathrm{mg} / \mathrm{L}$ IAA and $0.75 \mathrm{mg} / \mathrm{L} \mathrm{IBA}, \mathrm{b}, \mathrm{b} 1-\mathrm{JA} 20$ variety with an auxin concentration of $0.25 \mathrm{mg} / \mathrm{L}$ IAA and $0.75 \mathrm{mg} / \mathrm{L}$ IBA, c,c1 - IIHR WS 32 variety with an auxin concentration of $0.50 \mathrm{mg} / \mathrm{L}$ IAA and $0.50 \mathrm{mg} / \mathrm{L}$ IBA,d,d 1 - IIHR WS 48 variety with an auxin concentration of $0.25 \mathrm{mg} / \mathrm{L}$ IAA and $0.75 \mathrm{mg} / \mathrm{L}$ IBA. Growth Conditions- MediaHalf MS supplement with 3\% sucrose concentration, photoperiod-16 hours, culture period- 3 weeks at $25 \pm 2^{\circ} \mathrm{C}$.

Taiz and Zeiger (2002) reported that roots may require a less concentration of auxin to grow, but root growth is strongly inhibited by its higher level because at this level, auxin induces the production of ethylene, a root growth inhibitor. The adventitious roots were also induced in leaf explants of Withania somnifera using a combination of IAA and IBA by Praveen and Murthy (2010). Combination of IBA and IAA performed better than individual treatment of auxin upon adventitious root induction in Withania somnifera (Sivanandan et al 2012a). Wadegoankar et al (2006) reported that a combination of IAA and IBA was effective in adventitious rot induction in leaves of Withania somnifera .
Hence the best auxin concentration for adventitious root induction with 96.6\% root induction with 18.25 roots per explant was observed in Arka Ashwagandha variety with an auxin concentration of $0.25 \mathrm{mg} / \mathrm{L}$ IAA and $0.75 \mathrm{mg} / \mathrm{L}$ where as a combination $0.25 \mathrm{mg} / \mathrm{L}$ IAA and $0.75 \mathrm{mg} / \mathrm{L}$ IBA yielded in $97.2 \%$ root induction response and 15.12 roots per explant in JA 20. Induction response of $97.2 \%$ with 18.5 roots per explant was observed in an auxin concentration $0.25 \mathrm{mg} / \mathrm{L}$ IAA and $0.75 \mathrm{mg} / \mathrm{L}$ IBA of in IIHR WS 48 and induction response of $97.6 \%$ with 18.38 roots per explant was observed in explants inoculated into half strength MS medium with $0.50 \mathrm{mg} / \mathrm{L}$ IAA and $0.50 \mathrm{mg} / \mathrm{L}$ IBA for IIHR WS 32 .

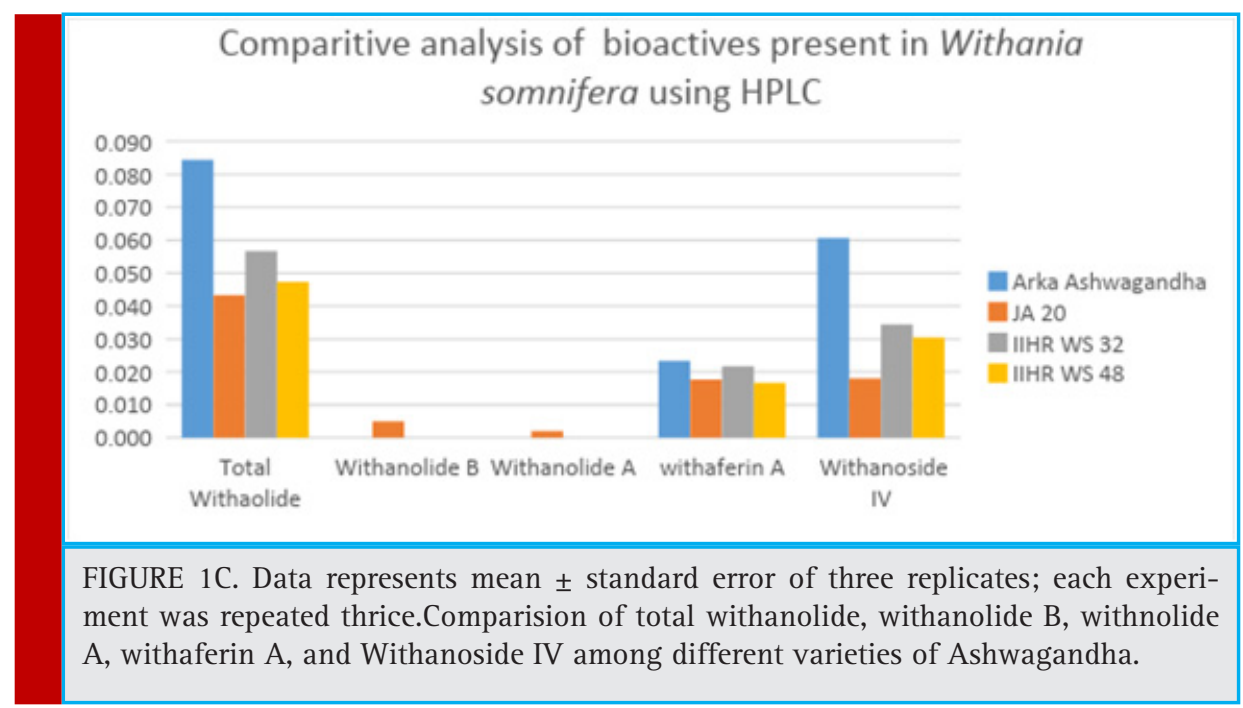




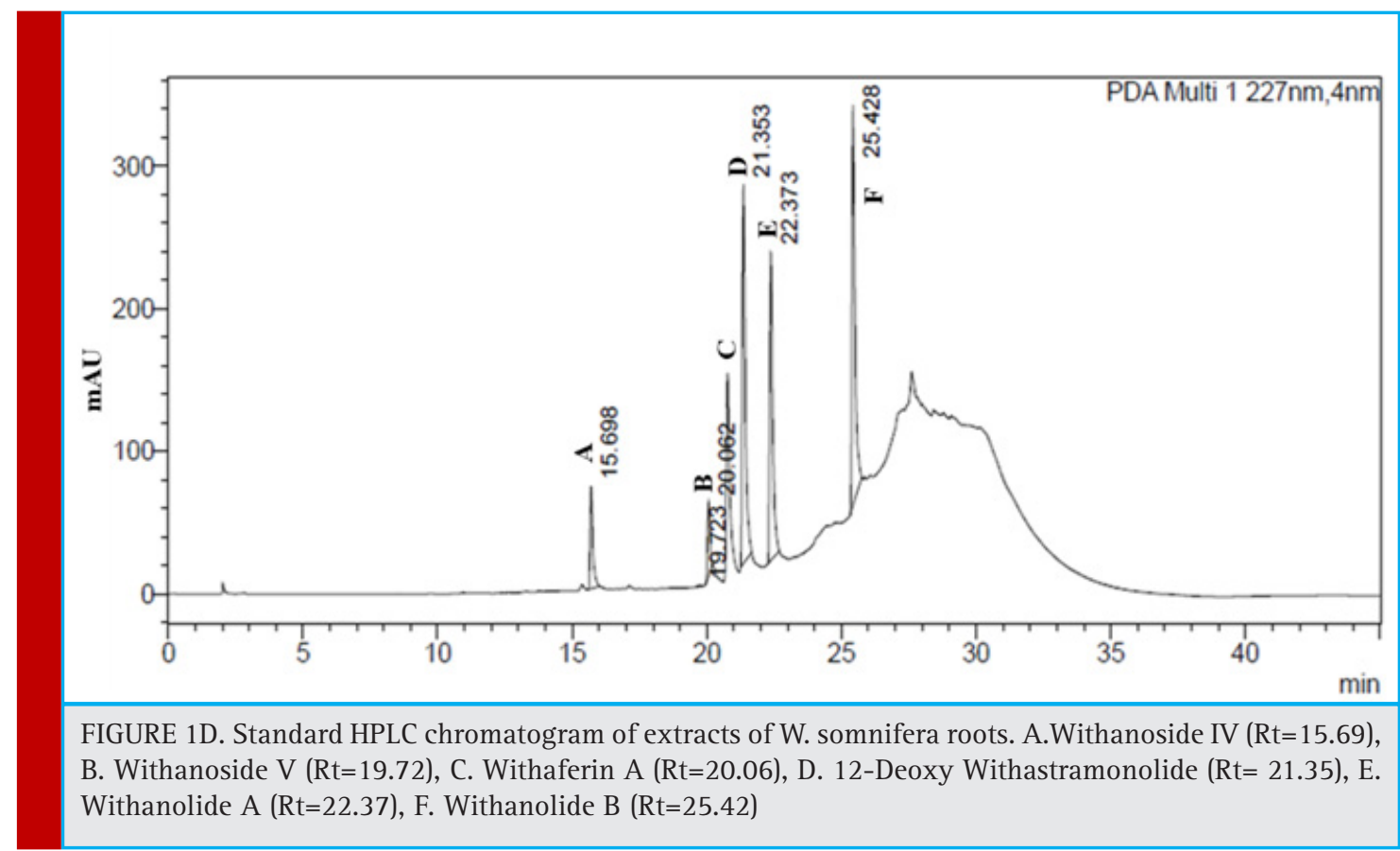

(Table 7 and 8), At the end of 15 day after explant inoculation, the length of the root was between $0.5-1.0 \mathrm{~cm}$ and it was observed that the root length steadily increased with the increase in growth period with was approximately 4-5 $\mathrm{cm}$ after 30 days. These results indicate fast growing nature of adventitious roots.

Table 7-Values are mean \pm standard error of five replications in three independent experiments, each with three explants per treatment. Means followed by the same letter are not significantly different at $\mathrm{P}<0.05$ according to Duncan Range Multiple Test. Data were scored after 15 days of culture. Growth Conditions- Media- Half MS supplement with selected auxin combination, photoperiod-16 hours, culture period- 3 weeks at $25 \pm 2^{\circ} \mathrm{C}$.

Table 8 - Values are mean \pm standard error of five replications in three independent experiments, each with three explants per treatment. Means followed by the same letter are not significantly different at $\mathrm{P}<0.05$ according to Duncan Range Multiple Test. Data were scored after15 days of culture. Growth ConditionsMedia- Half MS supplement with selected auxin combination, photoperiod-16 hours, culture period-3 weeks at $25 \pm 2^{\circ} \mathrm{C}$.

Variation persist in accumulation of withanolides due to plant parts, developmental stages (Praveen and Murthy, 2010), plant part obtained from different types of cultures (Sharada et al., 2007; Singh et al., 2017) of $W$. somnifera. These studies establish relationship between morphology/condition of plant tissue and withanolide contents. Sivanandhan et al., 2012b, 2013b; Singh et al.,
2017) used in vitro grown plants in different studies to develop adventitious roots, using different growth conditions. These developed roots were harvested to extract different combinations of withanolides.

The results for total withanolides analyzed in adventitious roots of four genotypes revealed significant difference among them (Table 9).

Among the genotypes, Arka Ashwagandha recorded high total withanolide content of $0.084 \%$ when compared to check JA-20 (0.043\%). Among seven withanolides analyzed, withanoside V, 12- deoxy Withanostramolide and Withanone were not detected in all genotypes and withanoside IV constitutes highest in all the genotypes. Withanolide A and B were detected only in JA-20. Arka Ashwagandha and IIHR WS-32 contain high withaferin A and Withanoside IV when compared to Check JA-20.

Table 9-Values are mean \pm standard error of three repeated experiments, each experiment was repeated thrice. Means followed by the same letter are not significantly different at $\mathrm{P}<0.05$ according to Duncan Range Multiple Test.

\section{CONCLUSION}

From the present research a standard protocol has been developed for mass production of adventitious roots from in-vitro leaves in Withania somnifera. A variety with highest total withanolide content has been identi- 
fied in comparision to JA 20. The requirement of dried plant material for withanolides drug production in India is high. Moreover, field cultivation is time consuming, laborious and not able to meet the Ashwagandha global market requirement. By transferring these roots in to suspension culture and mass propagating it in bioreactors reduce time gap compared to field grown roots and assure good quality Withania somnifera roots with high total withanolide content to cater the global demand. Large scale production through plant in vitro regeneration will provide a means of placing the plant onto the market at lower prices. In addition, the technique is cost effective, relatively simple and can be performed by semi-skilled persons.

\section{ACKNOWLEDGEMENTS}

The research was conducted in Indian Institute of Horticulture Research and was supported by centre for Post Graduation Studies Jain University. The author also acknowledges Department of Science and Technology for providing DST-Inspire fellowship for conducting this research.

\section{REFERENCES}

Agarwal A and Murali, B (2010) Estimation of withanolides in Ashwagandha by HPLC. Quality assessment of selected Indian medicinal plants. P: 241-243.

Geetha, M. and Rajashekar, S. (2017) Quality assessment of phytochemical analysis of Withania somnifera. International Journal of Current Research in Life Sciences Vol. 07, No. 04, pp.1435-1437.

Gould AR, Everett NP, Wang TL, Street HE (1981) Studies on the control of cell cycle in cultured plant cells: Effects of nutrient limitation and nutrient starvation. Protoplasma, 106 (1-2):1-13.

Kamaljit Kaur, Gurpreet Kaur and Ritesh Kaur (2017). Withania somnifera: An important herb in Ayurveda and IndeginousIndigenous medicinal system. Jour Pl Sci Res 33(2) 209222.

Kattimani KN, Reddy YN and Rajeshwar Rao BR Influence of pre- sowing seed treatment on seedling vigor, root length, and dry root yield of Ashwagandha (Withania somnifera (L.) Dunal) under semiarid climate of Hyderabad, J. Medicinal and Aromatic plant sciences, proceeding of national seminar, 22(4A) and 23(1A) (2000).

Kumar V, Kotamballi N, Chidambara M, Bhamid S, Sudha CG, Ravishankar GA (2005). Genetically modified hairy roots of Withania sominifera Dunal : A potent source of rejuvenating principles. Rejuvination Res. A: 37-45.

Murthy HN, Dijkstra C, Anthony P, White DA, Davey MR, Power JB, Hahn EJ, Paek KY (2008). Establishment of Withania somnifera hairy root culture for the production of withanolide A. J. Int. Plant Biol.50: 975-981.

Pandey V, Ansari WA, Misra P and Atri N (2017) Withania somnifera: Advances and Implementation of Molecular and Tissue Culture Techniques to Enhance Its Application. Front. Plant Sci. 8:1390

Pawar PK, Maheshwari VL (2004). Agrobacterium rhizogenes mediated hairy root induction in two medicinally important members of family Solanaceae. Indian J. Biotechol. 3: 414-417

Nagella P, Murthy HN (2011) Effects of macroelements and nitrogen source on biomass accumulation and withanolide- $\mathrm{A}$ production from cell suspension cultures of Withania somnifera (L.) Dunal. Plant Cell Tissue Organ Cult 104: 119-124.

Praveen N, Murthy HN (2011). Synthesis of Withanolide A depends on carbon source and medium $\mathrm{Ph}$ in hairy root cultures of Withania somnifera. Ind. Crop Prod. 35: 241-234.

Rao S, Teesta VK, Bhattrai A, Khushi K and Bhatt S (2012) In-vitro propogation of Withania sominifera and estimation of withanolides for neurological disorders. Journal of Pharmacognosy. 3(2): 85-87.

Rani , R., Khan, M.A Khayani, W.K,Ullah,S., Naeem I., Mirza.B.,2017. Metabolic signatures altered by in vitro temperature stress in Ajuga bracteosa Wall.ex.Benth.Acta physiol. Plant 39(4)97.

Ray S,Ghosh B, Sen S, Jha S (1996) Withanolide production by root cultures of Withania somnifera transformed with Agrobacterium rhizogenes. Planta Med. 62: 571-573.

Sharada M, Ahuja A, Suri KA, Vij SP, Khajuria RK, Verma V, Kumar A (2007). Withanolide production by in-vitro cultures of Withania somnifera and its association with differentiation. Biol. Plant 51: 161- 164.

Singh, P., Guleri, R., Angurala, A., Kaur, K., Kaur, K., Kaul, S. C., et al. (2017). Addressing challenges to enhance the bio actives of Withania somnifera organ, tissue, and cell culture based approaches. Biomed Res. Int. 2017:3278494

Sivanandhan G, Arun M, Mayavan S, Rajesh M, Jeyraj M, Kapil Dev G, Manickavasagam M, Selvaraj N, Ganapathi A (2012b). Optimization of elicitation condition with methyl jasmonate and salicylic acid to improve the productivity of withanolides in the adventitious root culture of Withania somnifera $(L$. Dunal. Appl. Biochem. Biotechnol. 168: 681-696.

Sivanandhan G, Kapil Dev G, Jeyraj M, Rajesh M, Arjunan A, Muthuselvam M, Manickavasagam M, Selvaraj N, Ganapathi A (2013b). Increase production of withanolide A, withanone and withaferrin A in hairy root culture of Withania somnifera (L.) Dunal elicited with methyl jasmonate and salicylic acid. Plant Cell Tissue Org. Cult. 114: 121-129.

Sivanandhan G, Rajesh M, Arun M, Jeyraj M, Kapil Dev G, Arjunan A, Manickavasagam M, Muthuselvam M, Selvaraj N, Ganapathi A (2013a). Effect of culture conditions ,cytokininins, methyl jasmonates and salicylic acid on the biomass accumulation and production of withanolides in multiple shoot culture of Withania somnifera (L.) Dunal using liquid culture. Acta Physiol. Plant. 35: 715-728. 
Sivanandhan G, Rajesh M, Arun M, Jeyraj M, Kapil Dev G, Arjunan A, Manickavasagam M, Muthuselvam M, Selvaraj N, Ganapathi A (2012a). Optimization of carbon source for hairy root growth and withaferrin A and Withanone production in Withania somnifera. Nat.Prod. Commun. 7:1271-1272.

Tariq Khan, Bilal Hyder Abbasi, Mubarak Ali Khan, Muhammed azim (2017) Production of biomass and useful compounds through elicitation in adventitious root cultures of Fagona indica. Industrial crops \&t products. 108(2017)451-457.

Wu Ch, Dewir YH, Hahn ej and Peak KY (2006) Optimization of culturing conditions for the production of biomass and pheno- lics from adventitious roots of Echinacea angustifolia. Journal of Plant Biology, 49(3):193-199.

Yin S, Liang Y, Gao W, Wang J, Jing S, Zhang Y and Liu H (2013) Influence of medium salt strength and nitrogen source on biomass and metabolite accumulation in adve4ntitious root cultures of Pseudostellaria heterophylla. Acta physiologiae Plantarum.

Zhang J, Yuan Gao W, Wang J, Li X (2012) Effects of sucrose concentration and exogenous hormones on growth and periplocin accumulation in adventitious roots of Periploca sepium Bunge. Acta Physiol Plant 34:1345-1351. 